\title{
Heterogeneity of Thermomechanical and Chemi-thermo- mechanical Pulps Described with Distributions of an Independent Common Bonding Factor on Particle Level
}

\author{
Olof Ferritsius, ${ }^{\mathrm{a}, *}$ Rita Ferritsius, ${ }^{\mathrm{a}, \mathrm{b}}$ Mats Rundlöf, ${ }^{\mathrm{c}}$ Sofia Reyier Österling, ${ }^{\mathrm{d}}$ and \\ Birgitta A. Engberg ${ }^{\text {a }}$
}

\begin{abstract}
Particles in mechanical pulp show a wide variety but are commonly described using averages and/or collective properties. The authors suggest using distributions of a common bonding factor, BIND (Bonding INDicator), for each particle. The BIND-distribution is based on factor analysis of particle diameter, wall thickness, and external fibrillation of several mechanical pulps measured in an optical analyser. A characteristic BIND-distribution is set in the primary refiner, depending on both wood and process conditions, and remains almost intact along the process. Doubledisc refiners gave flatter distributions and lower amounts of fibres with extreme values than single-disc refiners. More refining increased the differences between fibres with low and high BIND. Hence, it is more difficult to develop fibres with lower BIND. Examples are given of how BIND-distributions may be used to assess energy efficiency, fractionation efficiency, and influence of raw material. Mill scale operations were studied for printing-grade thermomechanical pulp (TMP), and board-grade chemithermomechanical pulp (CTMP), both from spruce.
\end{abstract}

DOI: 10.15376/biores.17.1.763-784

Keywords: Heterogeneity; Distributions; Spruce; TMP; CTMP; Wood fibres; Fibre analyser; Fibre bonding; External fibre fibrillation; Fibre wall thickness

Contact information: a: FSCN Research Centre, Mid Sweden University, SE-85170 Sundsvall Sweden; b: Stora Enso Kvarnsveden, SE-78183 Borlänge Sweden; c: Capisco, Mariehov Kanalbyn 108, SE-61492 Söderköping Sweden; d: Dalarna University, SE-79188 Falun, Sweden;

* Corresponding author: olof.ferritsius@miun.se

\section{INTRODUCTION}

Heterogeneity may be the most appropriate word to use when describing paper and board. At the same time, a high degree of uniformity in the end use characteristics of these products is highly appreciated. To be able to produce the products, a proper choice of papermaking process and pulp supply is important. Mechanical pulps are made from wood, which is a highly heterogeneous material. For deeper insight into how heterogeneous wood is "converted" to heterogeneous mechanical pulp in the refiner, preferably in a uniform way, it is essential to have access to a relevant description of the material that shows its character.

The purpose of this paper is to suggest a method that reflects the heterogeneity of the particles in mechanical pulps in terms of a common bonding factor on the particle level of long fibres. The authors' intention with this paper is not to try to give the "complete picture" of the nature of mechanical pulps. There are other aspects that are important for 
the description of a mechanical pulp, but these are outside the scope of this paper. Furthermore, the purpose is not to characterize the network of particles.

\section{Background}

\section{A heterogeneous material}

Wood, the raw material, is almost as heterogeneous as the products made from mechanical pulps. Division of wood into individual particles, i.e. the pulp, increases the possibility of variation in, e.g., size, shape, ultra-structure, surface properties, chemical composition, and configuration of wood polymers, as well as charged groups. Although these pulp particles vary greatly in several aspects, it is common to describe a pulp in terms of averages and collective properties. Some examples are average fibre wall thickness (measured on a mixture of thin-walled earlywood and thick-walled latewood fibres), tensile index of handsheets (all particles interacting to form a thin layer, which is then dewatered, pressed, and dried in a way that may or may not resemble the way the products are manufactured), and dewatering resistance (of a pad consisting of billions of particles). Paper makers and pulp makers commonly agree that uniformity is the most important characteristic of both the pulp and the paper. However, there is no consensus on how to define uniformity. Higher uniformity may make it possible to operate closer to quality borders.

\section{Independent factors}

Many authors point out the benefits of describing the character of pulp by few and independent properties (Steenberg 1957; Clark 1958, Clark 1978; Heikkurinen et al. 1991). Forgacs' (1963) approach to describe a mechanical pulp with (at least) two independent factors, the $S$-factor (shape) and the $L$-factor (length), is based on extensive microscopy studies in combination with handsheet properties. Strand (1987) used factor analysis on a huge database of pulp and handsheet properties to characterize mechanical pulps. Strand (1987) was able to derive two independent common factors reflecting "bonding" (Factor 1) and "fibre length" (Factor 2). Furthermore, Factors 1 and 2 correlate to the $S$ and $L$ factor, respectively. Examining a few independent common factors instead of several conventionally measured properties, which are more or less correlated, makes it easier to get an overview of the status of the processed material and to optimize the process. Strand's approach was applied at the Stora Enso Kvarnsveden mill in the 1990s (Ferritsius 1996; Ferritsius and Ferritsius 1997; Ferritsius and Ferritsius 2001). It was shown that it was possible to replace freeness and amount of long fibres with the independent common factors F1 (fibre bonding) and F2 (long fibre influence) to control the mechanical pulping process and manufacture products with more uniform properties. In order to understand the process and the material, Clark (1958) stresses the importance of examining independent fibre characteristics instead of "the complex freeness-burst-tear system that is discussed but almost defies analysis".

Although Forgacs (1963) proposed a long time ago that at least two factors are required to characterize mechanical pulps, there have still been efforts made to use only one factor. Below is an example, regarding the influence of the amount of longer fibres in pulp on the surface roughness of sheets. It is quite common to believe that a lower amount of longer fibres will always be favorable for a lower surface roughness. The relative amount of longer fibres is often expressed as the amount of fibres retained on the 16-mesh wire in a Bauer McNett fractionator (hence R16). In an article, it is argued that a higher amount of the longer fibre fractions tends to result in a higher surface roughness (Hill et al. 2017). 
However, generally, this does not hold, because the relation can also be the other way around. This is shown where six pulps from mills producing SC (super calendared) or LWC (lightweight coated) grades are compared where the amount of R16 is in the range $1 \%$ to $16 \%$ (Ferritsius and Rautio 2007). For a more complete picture, not only the quantity but also the quality of the longer fibres is important. One way to evaluate it could be to examine the tensile index of handsheets made of the Bauer McNett fraction 16 to 30, as proposed by Mohlin (1989). In the study by Ferritsius et al. (2014) the pulps with higher amount of R16 fraction exhibit a higher value of the tensile index of the 16 to 30 fraction that correlate well with a lower surface roughness. Further, in a study of twelve TMP (thermomechanical pulp) lines producing printing grades conducted to identify "best available technology," it is shown that a given level of surface roughness can be reached over a wide range in the amount of R16 fraction. In 1987, Strand showed that roughness was negatively correlated to Factor 1 "bonding" and positively correlated to Factor 2 "fibre length" (Strand 1987). Hence, both "quality" and "quantity" must be taken into account to extend understanding of the underlying reasons for changes in the properties of handsheets and paper. It is not the fibre length itself that gives a higher roughness, which shows that it is important to find the factors behind a certain pulp property. For deeper insight regarding the process and the material, it may be necessary to examine pulp on the particle level instead of the handsheet level. In this paper, the authors address the fibres' ability to conform and bond to each other, $c f$. Forgacs' S-factor and Strands bonding factor but applied on particle level. This is based on measurements of fibre dimensions using an optical fibre analyser.

\section{Common and uncommon ways to describe mechanical pulps}

Mechanical pulps are commonly characterized by measuring several pulp and handsheet properties. The authors have studied how frequently such variables are used in research by counting how many times each property occurs in the figures of conference proceedings, more specifically in the 23 International Mechanical Pulping Conferences (IMPCs) that were held between 1973 and 2018. The IMPC is the most important international conference in the field. Over 5000 figures were examined. The results clearly show that collective properties, such as freeness and tensile index, and a set of averages of fibre dimensions are the most common variables, as shown in Fig. 1.

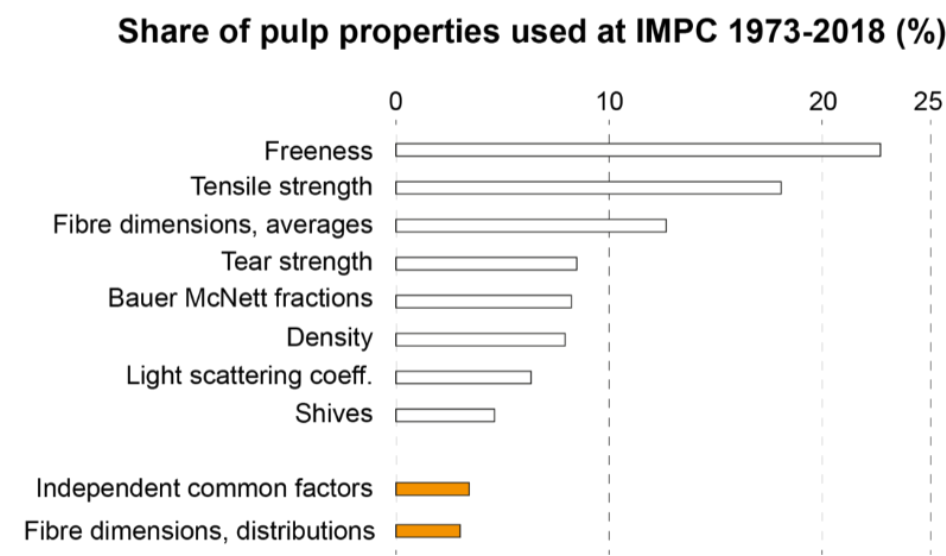

Fig. 1. Share (\%) of variables used in proceeding figures, IMPC 1973 to 2018 . Collective properties and averages are the most common variables to describe mechanical pulps. Independent common factors and distributions of fibre dimensions constitute 3 to $4 \%$ of the variables. 
Independent common factors constitute $4 \%$ of the variables, while a description of the distribution of fibre properties (heterogeneity) is even more rare, at $3 \%$. The "shives content" was as low as 5\% although shives are one of the main challenges for product quality when striving to operate at reduced levels of specific energy. Uniformity, process stability, raw material, and extractives were represented in few figures. Optical properties other than the light scattering coefficient, were not included in this survey.

Although less frequent, the heterogeneous nature of mechanical pulp fibres with respect to their cross-sectional dimensions were addressed in a handful of papers at IMPCs and also in journals. The focus has been to link wood and product character (Höglund and Wilhelmsson 1993), determine energy efficient operating conditions (Kure 1999), define fibre characteristics critical for handsheet properties (Reme 2000), compare fibre property distributions with averages (Pulkkinen et al. 2006), describe the heterogeneity of long fibres with respect to a measure of a bonding indicator (Reyier 2008; Reyier et al. 2008, 2012; Reyier Österling et al. 2015), and describe how the heterogeneity of the long fibres is developed from wood to final product (Ferritsius et al. 2009). Wood and Karnis (1979) state that "It is shown that average pulp properties do not adequately characterize a mechanical pulp with respect to its linting propensity". They presented the KW (Karnis Wood) fractionator, which gives a measure of the linting propensity of the pulp. A method to get a distribution in fibre flexibility by studying the bending characteristics of fibres in a laminar flow is reported by Forgacs et al. (1957). However, focusing on the extreme ends of the distributions, the "tails", is extremely rare.

\section{Tails - the extremes of distributions}

Describing a heterogeneous material in terms of distributions makes it possible to characterize it beyond average values that may hide useful information. There are some published works indicating the importance of a small fraction at an extreme end of a fibre distribution for the properties of the product. High quality printing surfaces is an important functional property of publication papers. One of the measures of this is a low number of missing dots. In order to find possible reasons for missing dots in gravure printing of SC paper, Provotas and Uesaka (2003) modelled the paper structure in 3D. They conclude that the presence of as small a fraction as $8 \%$ by weight of stiff and coarse fibres suffices to create quite large holes in the surface of the paper, which may cause missing dots. They also conclude that the fibre length did not significantly affect the amount of surface holes. In addition, Høydahl and Dahlqvist (1997) state that "a wide range of missing dots were found indicating a poor correlation against paper roughness measured with PPS (Parker Print Surface). The spread at any PPS-number is an average roughness measurement, concealing the micro roughness of the sheet surface created by the thick-walled, nonflattened fibres." These authors also state "further development of the SC-paper relies on the skill to control the dimensions of the individual fibres." Martorana et al. (2006) examined printed paper, looking for the origin of missing dots in gravure printing. In nearly all cases where there is a surface crater above a certain size, the absence of a dot, a missing dot, is detected. They also saw that sometimes a dot is missing in a position near large fibres. It seems that a small amount of stiff fibres may lead to craters and reduced printability.

Browning and Parker (1970) report that normal groundwood testing does not correlate to linting of the paper. Their approach is to examine the quality of groundwood by microscopy of the pit pulp from individual grinders. It was found that a single grinder out of a battery could cause problems when the paper made from a mixture of pulp from 
all grinders was printed. Browning and Parker (1970) summarise "It is interesting to note here that by examination of the groundwood it was now possible to forecast if a paper would give high lint, before it was actually made". Wood and Karnis (1979) built the KW fractionator, which separates particles in hydro cyclones in fractions with different linting propensity, PLPI (Pulp Linting Propensity Index). This device may be described as a "Bauer McNett classifier" with respect to Forgacs' $S$-factor and gives an indication of the propensity of a pulp to cause linting of papers. The authors state that the PLPI is a function of the distribution of bonding potential of the fibres and that it is enough that even lint candidates below $1 \%$, may cause problems with lint in the press room. Furthermore, they state that average pulp and handsheet properties cannot (not even the $S$-factor) predict the PLPI of mechanical pulps. The impact of stiff fibre elements on linting has also been reported by Syverud et al. (2007).

\section{Scope of the Present Work}

After some persistence, the current authors suggest that neither averages of fibre properties nor collective properties are sufficient to characterize mechanical pulps with respect to their influence on the functional properties of the end product. The authors therefore propose that measures that reflect the heterogeneity of the fibre material would be useful for a more profound understanding of and insight into the process and the material. The purpose of this paper is therefore to suggest a method that reflects the heterogeneity of the particles in mechanical pulps in terms of a common bonding factor on the particle level of long fibres. Fines are beyond the scope. In this paper, the authors have examined some examples of process design, process conditions, raw materials, and products. The examples are from independent studies at three mills operating under conventional conditions producing printing-grade TMP and board-grade CTMP from spruce.

\section{EXPERIMENTAL}

\section{Study 1: Factor Analysis Applied to Fibre Measurements and Handsheets of Fractionated Pulps}

The purpose of this paper is to suggest a method that reflects the heterogeneity of the particles in mechanical pulps in terms of a common bonding factor on the particle level of long fibres. In short, a wide range of mechanical pulps produced from spruce (Picea abies L. Karst.) were fractionated one-by-one in a four-stage hydrocyclone system to give five fractions each (c.f. the similarity to the KW fractionator mentioned in the background). These fractions were fractionated in a Bauer McNett device (Paper Test Equipment, Áby, Sweden). The fractions P16 to R30 and P30 to R50 mesh were run in an optical fibre analyser (FiberLab ${ }^{\mathrm{TM}}$, Kajaani, Finland) and analysed for fibre diameter, fibre wall thickness, external fibrillation, and length. In total about 30,000 fibres were analysed per fraction as a triplicate sample. In parallel, handsheets of the fractions P16 to R30 and P30 to R50 mesh of the cyclone fractions were made ( $c f$. Mohlin 1989) and analysed for tensile index and apparent density. For details, see previous cited studies (Reyier 2008; Reyier et al. 2008, 2012; Reyier Österling 2015). The pulps studied where double-disc (DD) TMP of news and SC grade, single-disc TMP of news grade, single-disc CTMP of board grade, and SGW pulp (stone ground wood) of SC grade. Factor analysis was performed on data of fibre diameter, fibre wall thickness, external fibrillation, and tensile index and apparent 
density of the handsheets made from the total of twelve fractions per pulp with a standard software (FactNet 5.0, Valmet AB, Sundsvall, Sweden). The principle of factor analysis is to derive a number of independent common factors and determine how much of the total variations in the measured properties they can explain. For further details see e.g., Strand (1987). Excess kurtosis was calculated according to Westfall (2014).

\section{Study 2: Influence of Process Design and Process Conditions}

The TMP samples were taken at two mills producing newsprint grade paper. The raw material in the mills were Norway spruce (Picea abies L. Karst.). In mill 1 there was one line with single-disc refiners (one rotor and one stator) of Valmet CD (conical disc) type in the primary stage followed by a screen room with screens and hydro cyclones and flat single-disc reject refiners. The other line in mill 1 was equipped with double-disc (DD) refiners (two counter rotating rotors) of Valmet DD type in the primary stage followed by a screen room with screens and hydro cyclones and double-disc reject refiners. The refiners were operating under the mill normal conditions, at production levels in a range of 6 to 14 $\mathrm{bdmt} / \mathrm{h}$. The specific energy in the primary refiners was about $1,950 \mathrm{kWh} / \mathrm{bdmt}$ (CD) and $1,700 \mathrm{kWh} / \mathrm{bdmt}(\mathrm{DD})$, respectively. Total refiner specific energy was approximately 2,200 $\mathrm{kWh} / \mathrm{bdmt}(\mathrm{CD})$ and 2,000 $\mathrm{kWh} / \mathrm{bdmt}(\mathrm{DD})$, respectively, to produce pulp aimed for newsprint grade. A portion of the news grade TMP produced in the DD refiners were further refined to SC grade in single-stage DD refiners of the same type as in the primary refiner stage at a total specific energy of approximately $3,100 \mathrm{kWh} / \mathrm{bdmt}$.

Samples were taken over a period of five months in several positions such as main line refining, before and after rejects refiner, and final pulp. Every sample is based on an average of at least five composite samples taken during eight $h$. Each sample consisted of at least 20 grab samples. In mill 2, where newsprint was produced from Norway spruce, there was one line with single-disc refiners of Andritz Twin (Andritz AG, Graz, Austria) type in the primary and secondary stage followed by a screen room with screens and a single-disc reject refiner. The refiners were operating under for the mill normal conditions and production level $15 \mathrm{bdmt} / \mathrm{h}$ and specific energy in the level of $1,100 \mathrm{kWh} / \mathrm{bdmt}$ in the primary stage and $900 \mathrm{kWh} / \mathrm{bdmt}$ in the secondary. The total applied specific energy in the refiners including the reject stage was $2,200 \mathrm{kWh} / \mathrm{bdmt}$. Samples were taken as composite samples over $1 \mathrm{~h}$ after the primary, secondary main line stage, and after disc filter.

All pulps were stored in plastic bags (PE) in a freezer $\left(-18{ }^{\circ} \mathrm{C}\right)$ at consistencies above $30 \%$. Prior to analysis, the pulps were hot disintegrated (ISO 5263-3). The pulps were then analysed in a FiberLab ${ }^{\mathrm{TM}}$ device (Kauppinen, Kajaani: FiberLab ${ }^{\mathrm{TM}}$, V3.5, Kajaani, Finland) for fibre wall thickness, fibre diameter, and external fibrillation. The length of the particles was analysed according to the ISO 16065-2 (2014) standard. Each duplicate sample was run three times in the analyser; each run contained at least 10,000 measured particles.

\section{Study 3: Influence of Raw Material}

The trial was performed in a CTMP plant producing board grades. The wood raw materials were three types of Norway spruce (Picea abies L. Karst.): chips produced from $100 \%$ round wood, $100 \%$ saw mill chips, and a 50/50 mix of the two. Moisture content of the chip assortments were 59\% (saw mill), 56\% (50/50 mix), and 53\% (round wood). The chip refiner was a Valmet CD equipped with a $24 \mathrm{MW}$ motor (Valmet AB, Sundsvall, Sweden). The production level was $25 \mathrm{bdmt} / \mathrm{h}$. 
The chips were impregnated with sodium sulphite, at a level typical for this application, at alkaline $\mathrm{pH}$. Each of the chip assortments were run at three levels of specific energy input by adjusting the flow rate of the dilution water to the flat zone of the refiner. This gave a range in the specific energy input of 610 to $740 \mathrm{kWh} / \mathrm{bdmt}$, and a range in refiner load from 16 to $19 \mathrm{MW}$.

CTMP from each chip assortment was produced during a period of four $h$. Composite samples of the screened chips going to the presteaming bin were collected during a 20 min period before taking the CTMP samples. Composite pulp samples were collected from the latency chest for $20 \mathrm{~min}$ for each level of specific energy input. Each composite sample consisted of about 40 grab samples. Before the samples were taken, the refiner was running for one $\mathrm{h}$ without changing the set points of the process variables.

The pulp samples were analysed as described under Study 2. The chip samples from the mill trial were also digested in a laboratory kraft cook to a yield of $49 \%$ to be able to measure the fibre dimensions of the raw material. In addition, a portion of the CTMP samples were also digested in a laboratory kraft cook (Ferritsius et al. 2018). After hot disintegration the digested samples of wood and CTMP were analysed in a FiberLab ${ }^{\mathrm{TM}}$ device (Valmet Automation Oy, Kajaani, Finland) in the same manner as the original CTMPs. The trial layout is illustrated in Fig. 2.
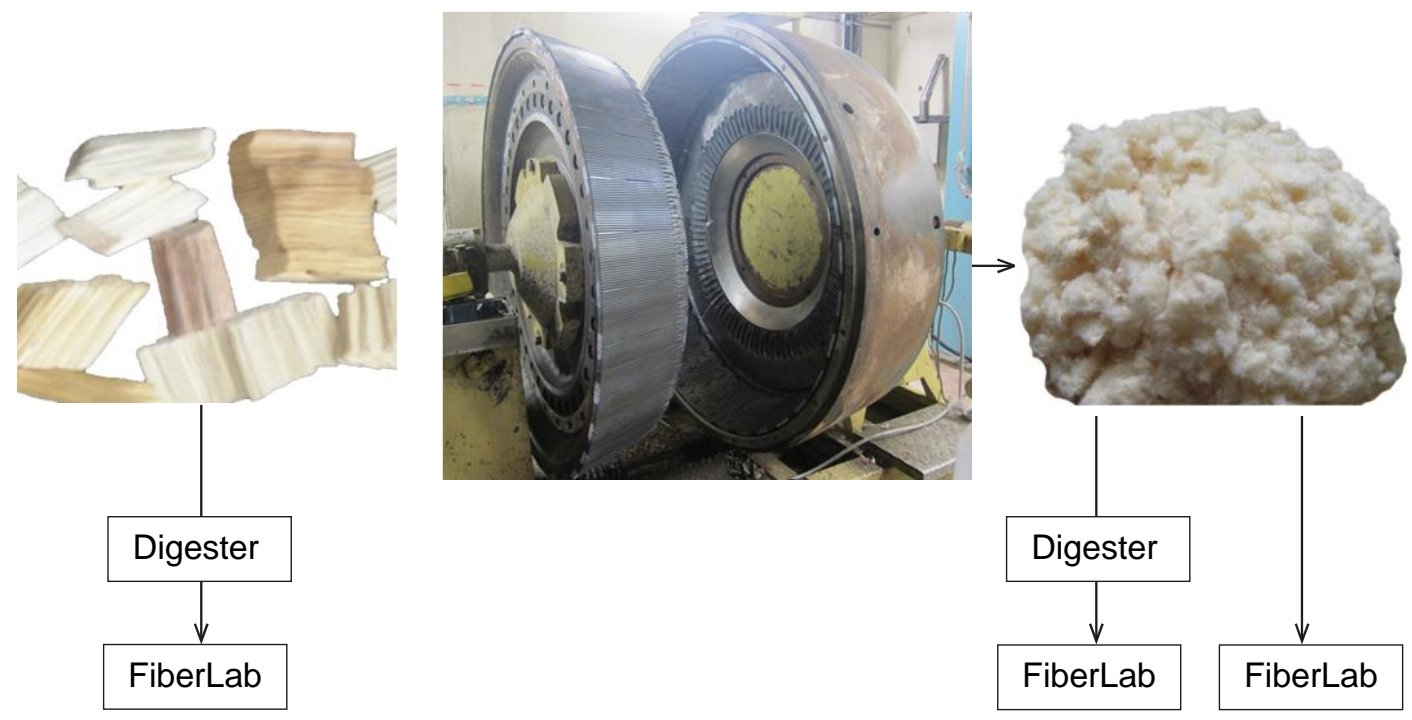

Fig. 2. Illustration of raw material study; raw material was chips produced from $100 \%$ round wood, $100 \%$ saw mill chips, and a $50 / 50$ mixture of the two

\section{Study 4: Fibres in (Printed) Papers}

Paper samples from mill 1 mentioned in Study 1 and printed paper produced in two other mills were treated in the following way: Approximately $0.5 \mathrm{~g}$ paper were immersed in $250 \mathrm{~mL}$ distilled water and disintegrated by hand for approximately two min in a glass cylinder with a piston with a perforated disc until no paper flakes were visible. The samples were analysed in a FiberLab ${ }^{\mathrm{TM}}$ device as mentioned above. 


\section{RESULTS}

\section{Factor Analysis Applied on Particle Level}

As mentioned in the introduction, Strand (1987) applied factor analysis to a big database of pulp and handsheet properties of mechanical pulps and found two independent common factors. These factors explain approximately $90 \%$ of the variations of these properties. In the late 1990s, the authors started to develop a method at Stora Enso with respect to the distribution of a measure that reflected the "bonding"-factor on particle level. Factor analysis was performed on the data from the analyses of the pulp fractions mentioned under the 'Experimental' section, under Study 1. It was found that a single factor could describe approximately $70 \%$ of the variations in three variables the authors obtained from FiberLab ${ }^{\mathrm{TM}}$ (wall thickness, fibre diameter, and external fibrillation), as well as tensile index and apparent density of the handsheets, all analysed on pulp fractions. This factor was called BIND, Bonding INDicator. A higher value of BIND corresponded to fibres that gave handsheets of Bauer McNett fractions with a higher level of apparent density and tensile index. The BIND factor is dimensionless and has the form shown in Eq. 1 ,

$$
\mathrm{BIND}=a+b \times D_{f}+c \times T_{w}+d \times F_{\text {ext }}
$$

where $D_{\mathrm{f}}$ is fibre diameter $(\mu \mathrm{m}), T_{\mathrm{w}}$ is fibre wall thickness $(\mu \mathrm{m}), F_{\text {ext }}$ is external fibre fibrillation (\%), and $a$ through $d$ are constants. The BIND was negatively correlated to fibre diameter and fibre wall thickness, while it was positively correlated to external fibrillation.

The BIND was then calculated according to Eq. 1 for all individual particles in the length range of 0.7 to $2.3 \mathrm{~mm}$. The reason for selecting a length interval was to fit to the 16- to 50-mesh interval in the Bauer McNett method. In order to find out how different the fibres (particles) are in a pulp, the particles may be divided into for instance five groups based on the level of BIND. Each group then represented $20 \%$ of the population by number. Table 1 shows average values of parameters for fibres from news grade TMP produced in single- and double-disc refiners. The average properties of the particles in the groups exhibited a wide range for each of the pulps. In all classes, the double-disc TMP exhibited a lower level of fibre wall thickness index and a higher degree of external fibrillation compared to the TMP produced in single-disc refiners. The next sections will show how the distributions of BIND reflected processes, process stages, and raw material with respect to the heterogeneity of the material.

Table 1. Average Particle Properties for News Grade TMP Produced in Singledisc and Double-disc Refiners

\begin{tabular}{|c|c|c|c|c|c|c|c|c|c|c|}
\hline & \multicolumn{4}{|c|}{ Single-disc TMP } & \multicolumn{5}{c|}{ Double-disc TMP } \\
\hline Group \# & 1 & 2 & 3 & 4 & 5 & 1 & 2 & 3 & 4 & 5 \\
\hline BIND & 98 & 100 & 102 & 104 & 109 & 98 & 101 & 103 & 105 & 110 \\
\hline$T_{\mathrm{w}}$, Wall Thickness $(\mu \mathrm{m})$ & 17 & 12 & 8 & 5 & 3 & 16 & 11 & 7 & 4 & 2 \\
\hline$D_{\mathrm{f}}$, Fibre Diameter $(\mu \mathrm{m})$ & 38 & 32 & 30 & 27 & 26 & 42 & 33 & 28 & 25 & 23 \\
\hline$F_{\text {ext, }}$ External Fibrillation $(\%)$ & 2.6 & 3.4 & 4.1 & 6.2 & 18 & 3.1 & 3.9 & 5.2 & 8.3 & 22 \\
\hline
\end{tabular}

Each group represented $20 \%$ of the population by number 


\section{Influence of Process Design and Process Conditions}

In the authors' approach to visualising the heterogeneity of mechanical pulps with respect to a common bonding factor, the authors chose to plot distributions of the BIND. This is illustrated in Fig. 3 for primary stage and final TMP produced in single-disc refiners and double-disc refiners. Schematic drawings of fibre cross-sections and degree of external fibrillation are included as a visualisation of BIND in both ends of the scale. The figure clearly shows differences in the shape of the distributions of the fibres from the two refiner types. The distributions in BIND values were wide around the averages and far from being Gaussian. Both refiner types gave pulps that were skewed to the right. Double-disc refiners gave more of a plateau, while single-disc (CD) refiners gave a sharper peak skewed towards the left. Kurtosis values of the distributions also showed a difference between the particles from the two refiner types. A normal distribution has an excess kurtosis of zero, and a higher kurtosis means longer tails (higher number of more extreme values). Excess kurtosis of the data for the double-disc refiner had a value of 2.8, while it was higher at 3.3 for the single- disc refiners. Such differences among the fibres are impossible to detect by only examining average values or collective properties such as from handsheet testing. The importance of the primary refiner stage with respect to the character of the final pulp, which has been known for a long time, is shown for the BIND distributions in Fig. 3. It can be seen that the distribution of BIND was set in the primary refining stage for both single- and double-disc refiners. Kure expressed the importance of the primary refiner stage with respect to the fibre properties in the following way: "It is difficult to change the character of the fibres once they are refined" (Kure 1999), which fits well with the distributions shown in Fig. 3.

Because the raw material fed to the two refiner lines was the same, it is most probably the type of refiner and the conditions in the refiners that has set the characteristic "fingerprints" shown here as the BIND distributions. The presence of the differences remains to be explained; the explanation could be the basis for greater insights into the mechanisms of fibre treatment in the refiners and how it is reflected in the properties of the final products.

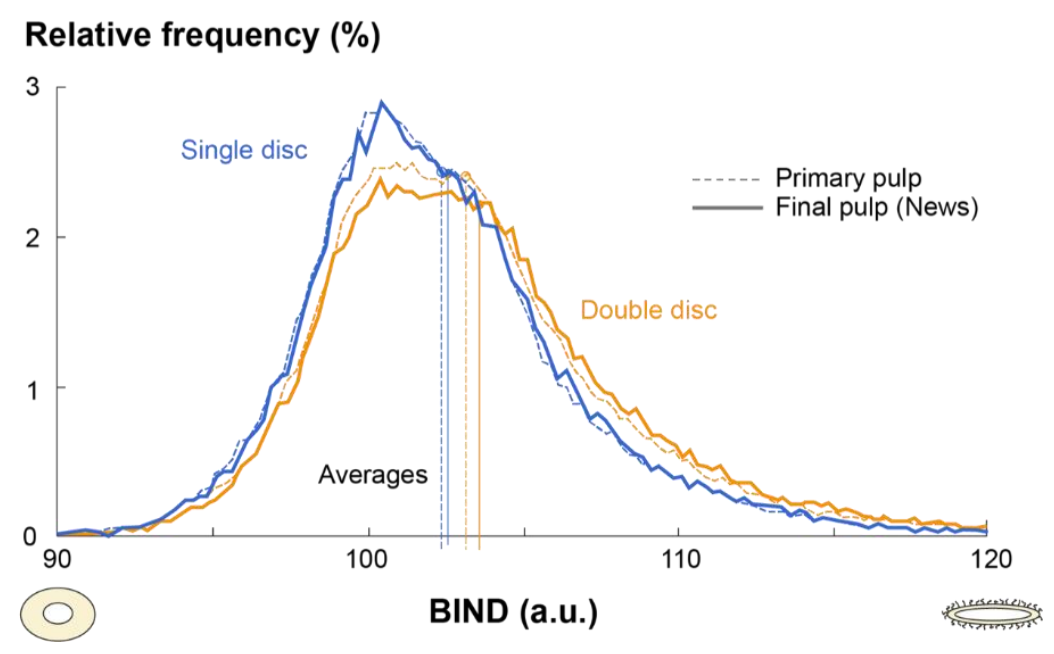

Fig. 3. The shape of the distribution of BIND is set in the primary refining stage. Averages are from left to right: Single-disc primary and final news grade followed by double-disc primary and final News grade 
Two types of single-disc refiners were compared, single-stage CD refiners with two refiner zones in series in mill 1 and single-disc twin refiners in series with two parallel refiner zones in mill 2, as shown in Fig. 4. The average in the BIND was higher with the twin-refiners but there were slightly more fibres of low values in the BIND but also more fibres of high values.

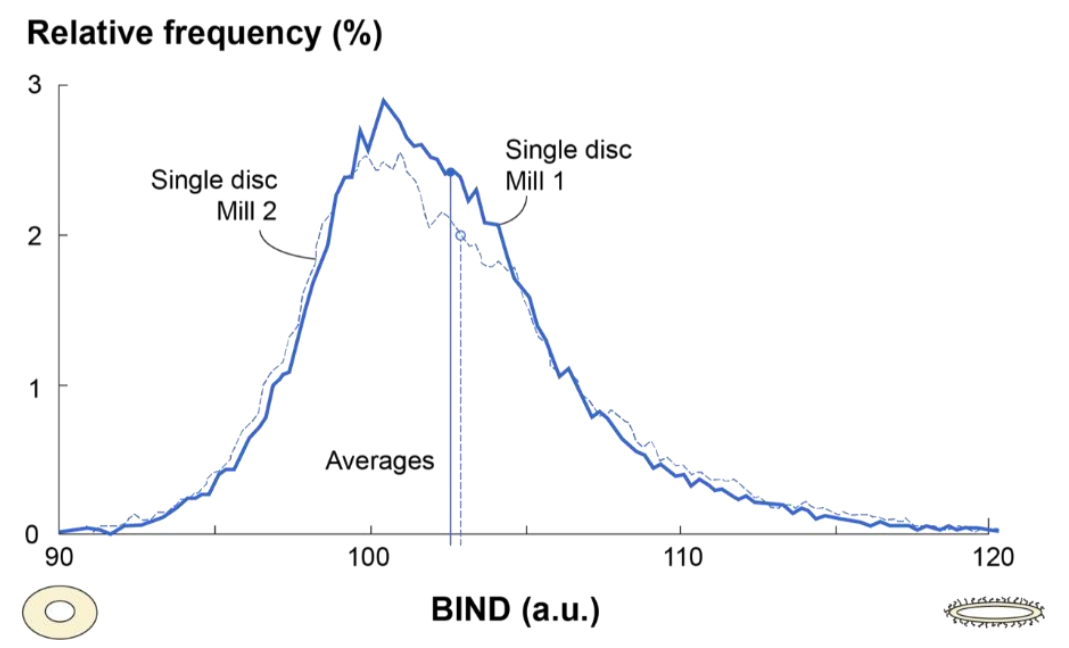

Fig. 4. Refiners in Mill 2 had a wider distribution and higher amount of "low bonding" fibres compared to Mill 1, although the average was higher (vertical lines)

This wider distribution is impossible to detect by examining averages and unlikely to be detected using handsheet properties but may influence the properties of the product. Furthermore, it can be seen in the figure that the two peaks were similar for these singledisc refiners. However, because the two raw materials have not been analysed thoroughly, it cannot be argued that the characteristics of the produced pulps were the result of the processes conditions only.

Although the average values of the BIND of the primary and final pulps differed as shown in Fig. 3, the two distributions largely overlapped. Nevertheless, the increase in BIND from primary to final pulp could be caused by what happened in the fractionation stage and in the refining of the rejects. The main objective of a screening and cleaning system is to fractionate particles that need to be further developed.

To what extent the fibres from the primary refiner stage in the main line were separated with respect to the BIND for the double-disc line is illustrated in Fig. 5. The shape of the reject curves corresponded to the shape of the unscreened primary stage fibres, which may be interpreted as the particles were only fractionated to a minor extent. There was a rather wide distribution with respect to the BIND of the particles in the rejects. When specific energy was applied in the reject refiner, at maintained fibre length, parts of the curve shifted towards higher values of the BIND.

To further study how fibres were developed, the development in the BIND was examined along a TMP line for SC grade. In the primary stage double-disc refining 1,700 $\mathrm{kWh} / \mathrm{bdmt}$ was applied. The TMP of final news grade was produced at a total of 2,000 $\mathrm{kWh} / \mathrm{bdmt}$. A part of this pulp was then refined in double-disc refiners at high consistency at $1,100 \mathrm{kWh} / \mathrm{bdmt}$ to reach a total of $3,100 \mathrm{kWh} / \mathrm{bdmt}$ for the SC grade TMP. The shape 
of the distribution in BIND remained rather unaffected over the quite large range of energy input, Fig. 6. This shows a characteristic "fingerprint" with respect to the BIND of fibres, which seemed to be set in the first stage chip refiner.

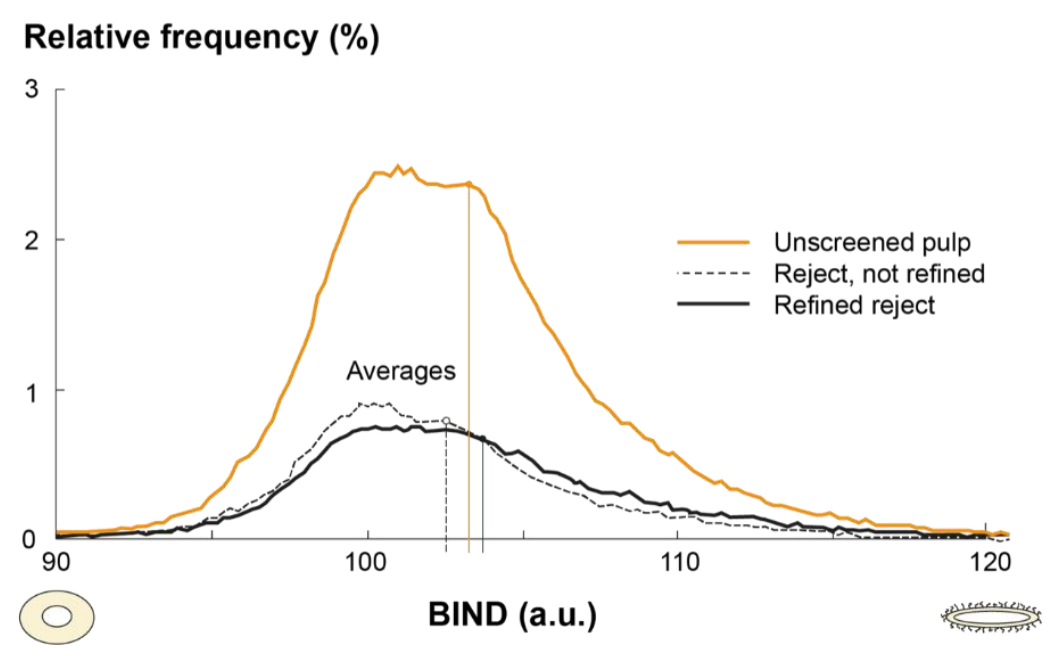

Fig. 5. BIND for primary stage unscreened, unrefined rejects, and refined rejects in the doubledisc line. The area under the reject curves corresponds to the reject rate

The averages increased with increasing energy input. Again, it can be seen that the distribution of BIND values exhibited a wide range around the average for each level of specific energy. Not only were the averages affected by increased applied specific energy, but also the tails of the distributions.

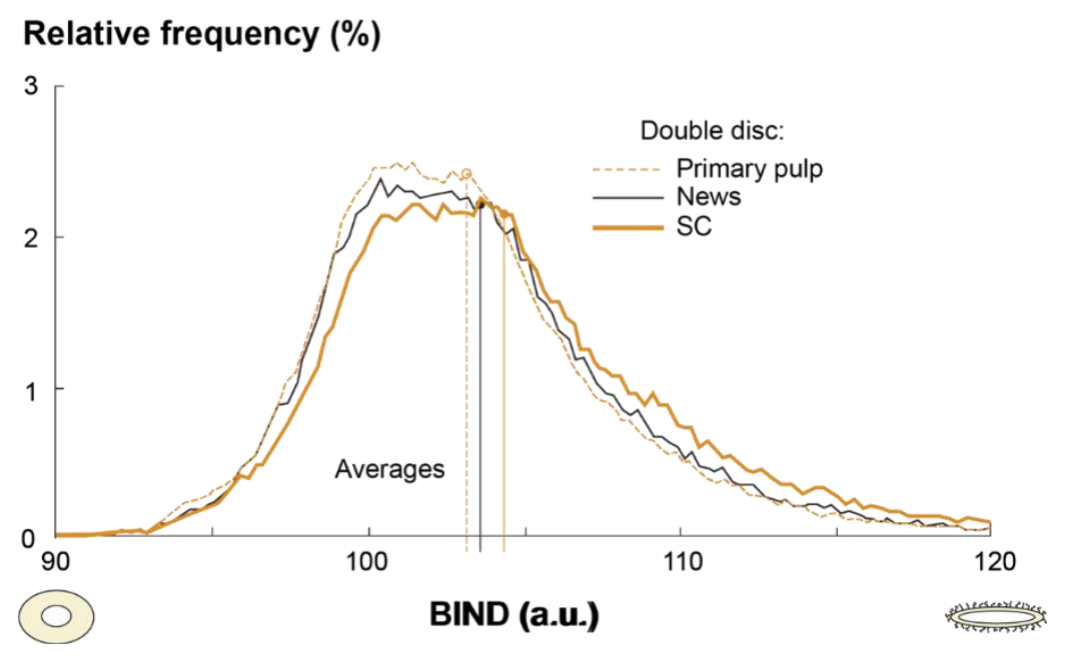

Fig. 6. Distribution in the BIND remained rather unaffected when increasing specific energy

In order to obtain a value that reflects how far away the two tails of a distribution are from each other, the following definition of "wideness", F 0.90, was made (Eq. 2),

$$
F 0.90=95^{\text {th }} \text { percentile }-5^{\text {th }} \text { percentile }
$$


which shows how wide the distribution of the BIND was when $90 \%$ of the population was covered. Using this number, it could easily be noted that when more energy was applied in the refiner, the distribution of BIND became wider. This in turn indicated that some fibres were developed to a larger extent than others. The particles with the lowest BIND, $5^{\text {th }}$ percentile, were developed to a lower extent compared with the fibres with the highest BIND, $95^{\text {th }}$ percentile. This is shown in Fig. 7 where the two levels of percentile are plotted against applied specific energy.

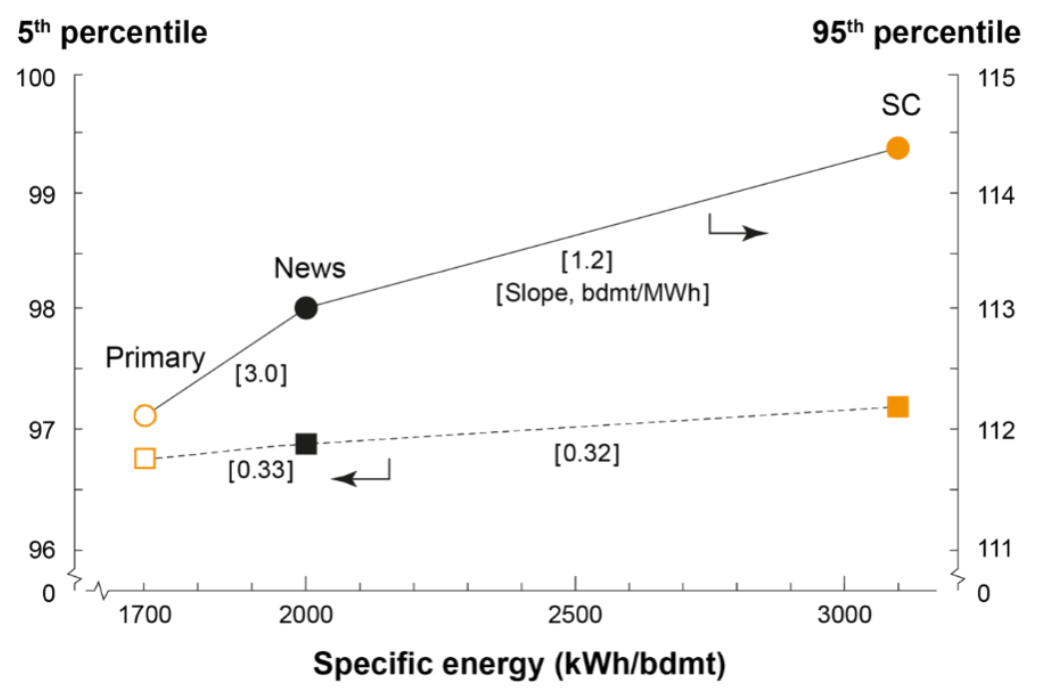

Fig. 7. Fibres with higher BIND, 95 th percentile, increased BIND more than fibres with lower BIND, $5^{\text {th }}$ percentile; numbers within brackets indicate the slope

The slope of the $95^{\text {th }}$ percentile from primary stage to news grade was 3.0 bdmt/MWh, while it was 0.33 for $5^{\text {th }}$ percentile. In other words, the tail with particles of high BIND were developed nine times more efficiently compared to the particles on the lower end of the distribution. The slope of the $95^{\text {th }}$ percentile from news grade to SC grade was $1.2 \mathrm{bdmt} / \mathrm{MWh}$, while it was 0.32 for $5^{\text {th }}$ percentile corresponding to four times more efficiency for the particles of high BIND. The distributions in BIND did make it possible to study in more detail to what extent particles of different levels in BIND developed in refining.

For greater insight into the mechanisms in defibration and how particles are further refined the authors are quite convinced that it is of interest for any refiner type to examine how the distribution in BIND may be controlled and also modelled by the type of process, the conditions in the refiner, and the type of raw material. The next section will deal with some aspects of how a set of raw materials influenced the BIND distributions.

\section{Influence of Wood Raw Material}

According to Steenberg (1975), "It is more or less auxiomatic that any process which give close to $100 \%$ yield will make a product which strongly reflects variations in the raw material". Höglund and Wilhelmsson (1993) has a similar view, saying that "The type of wood used evidently gives its character to the long fibre fraction after refining". In mill scale, the influence of the raw material on the corresponding CTMP of board grade was examined. Raw materials were spruce chips produced from 100\% round wood, 100\% saw mill chips, and a 50/50 mixture of the two. These assortments were digested in a 
laboratory kraft cook and analysed with respect to their fibre dimensions in FiberLab ${ }^{\mathrm{TM}}$. The corresponding CTMPs were also analysed for fibre dimensions.

The fibres from saw mill chips exhibited a distribution shifted towards the higher end with respect to the fibre wall thickness index compared to the chips from round wood. A similar pattern of fibre wall thickness index was exhibited by the corresponding CTMPs, except that there were relatively more fibres with a low level of wall thickness for CTMP based on saw mill chips. In the present study, the CTMP based on saw mill chips exhibited a higher degree of fibrillation of the particles compared to the other two assortments. Summarized in terms of the BIND distributions the examined fibre characteristics of the CTMPs painted a picture where the saw mill chips resulted in wider distributions compared to the round wood chips, as shown in Fig. 8. The mixed chip assortment was between the two pure chip types. One of the reasons for the wider distribution in the BIND for CTMP from saw mill chips is probably that the raw material exhibited wider distributions in terms of fibre wall thickness index and fibre diameter. The overall picture showed that the heterogeneity of the raw material was largely reflected in the corresponding CTMP. This is illustrated in Fig. 8, where the distribution in the BIND is plotted for the three levels of applied specific energy for each raw material assortments.

In this study there was a larger difference in the BIND distributions due to the raw material compared to the level of applied specific energy. The higher degree of heterogeneity for CTMP from saw mill chips was reflected in higher amounts of both long fibres and fines (Ferritsius et al. 2018). In a coming publication the current authors will discuss the influence of raw material on the distribution in the BIND in more detail.

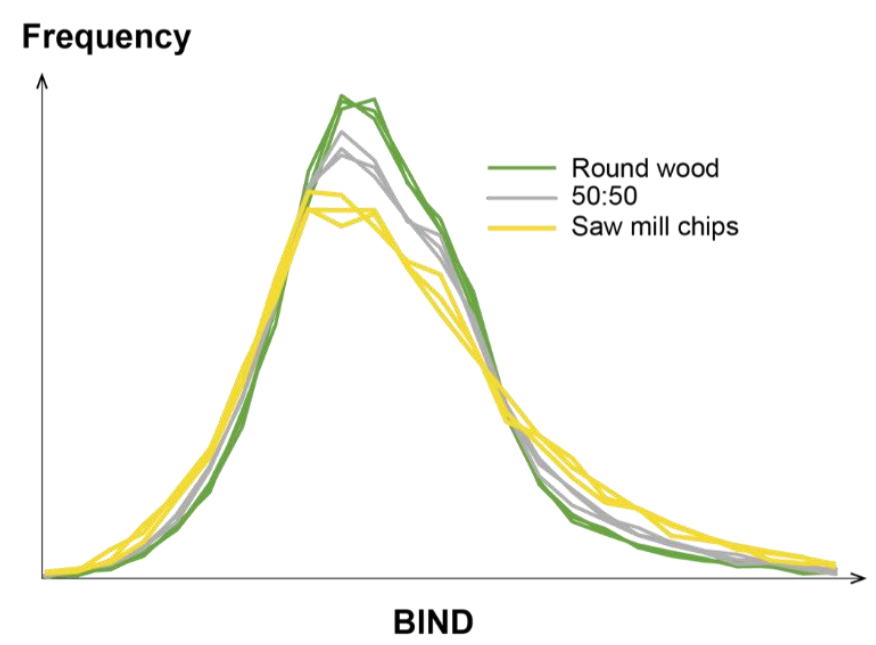

Fig. 8. Distributions of BIND for CTMPs at three levels of applied specific energy for three assortments of spruce raw material

\section{Fibres in (Printed) Papers}

Within certain limits, the most important property of fibres intended for paper making is uniformity over time. A consistent quality of the furnish is of great value for the paper and board makers. Even fluctuations towards the high-quality side may create disturbances. However, it is sometimes unclear which property/properties that should be uniform and how to define quality, which may differ from mill to mill and from person to person. The demands on fibre quality ought to be defined by the paper and board makers. In order to shed some light on this challenging issue the authors have analysed a final 
product made from 100\% TMP, a machine-made standard newsprint, with respect to its distribution in the BIND. This paper product was made of a mixture of TMPs produced in single- and double-disc refiners. The authors found that the distribution of the BIND in the furnish corresponded well with the BIND distribution of the disintegrated paper, as shown in Fig. 9.

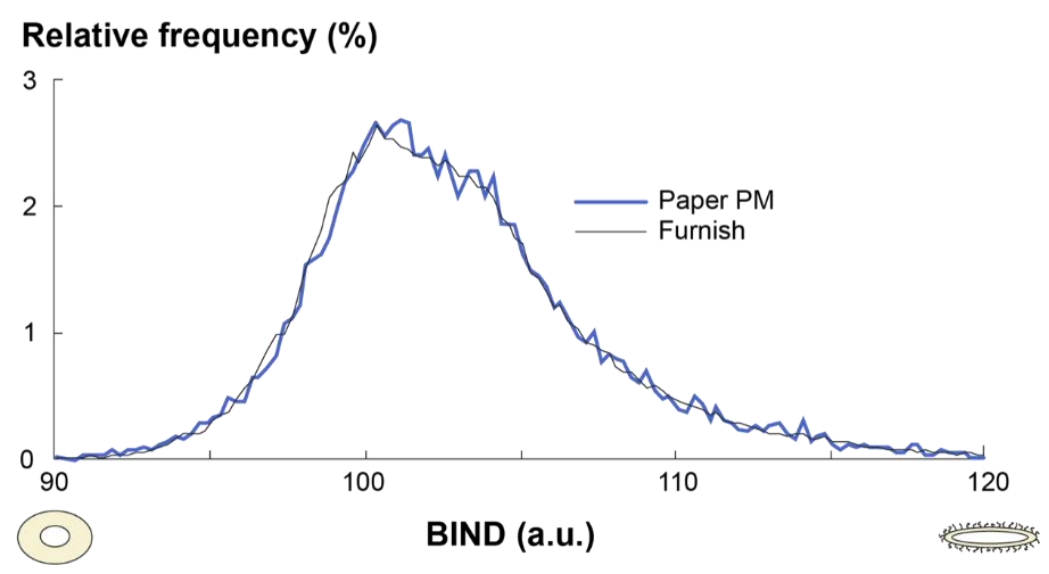

Fig. 9. BIND distribution for paper of news grade and the corresponding furnish

Inspired by this way of analysing paper and comparing it to the pulp, the authors were curious to see what could be learned by examining paper samples obtained from colleagues in other mills. Therefore, the authors purchased a copy of the newspaper Sundsvalls Tidning, printed on paper produced at the SCA Ortviken, Sweden paper mill. At Ortviken, there were only double-disc refiners in the primary refiner stage, and Norway spruce was the wood raw material. The BIND distribution exhibited a "fingerprint" similar to the fibres from the double-disc refiners in Kvarnsveden, Sweden, as shown in Fig. 10A.
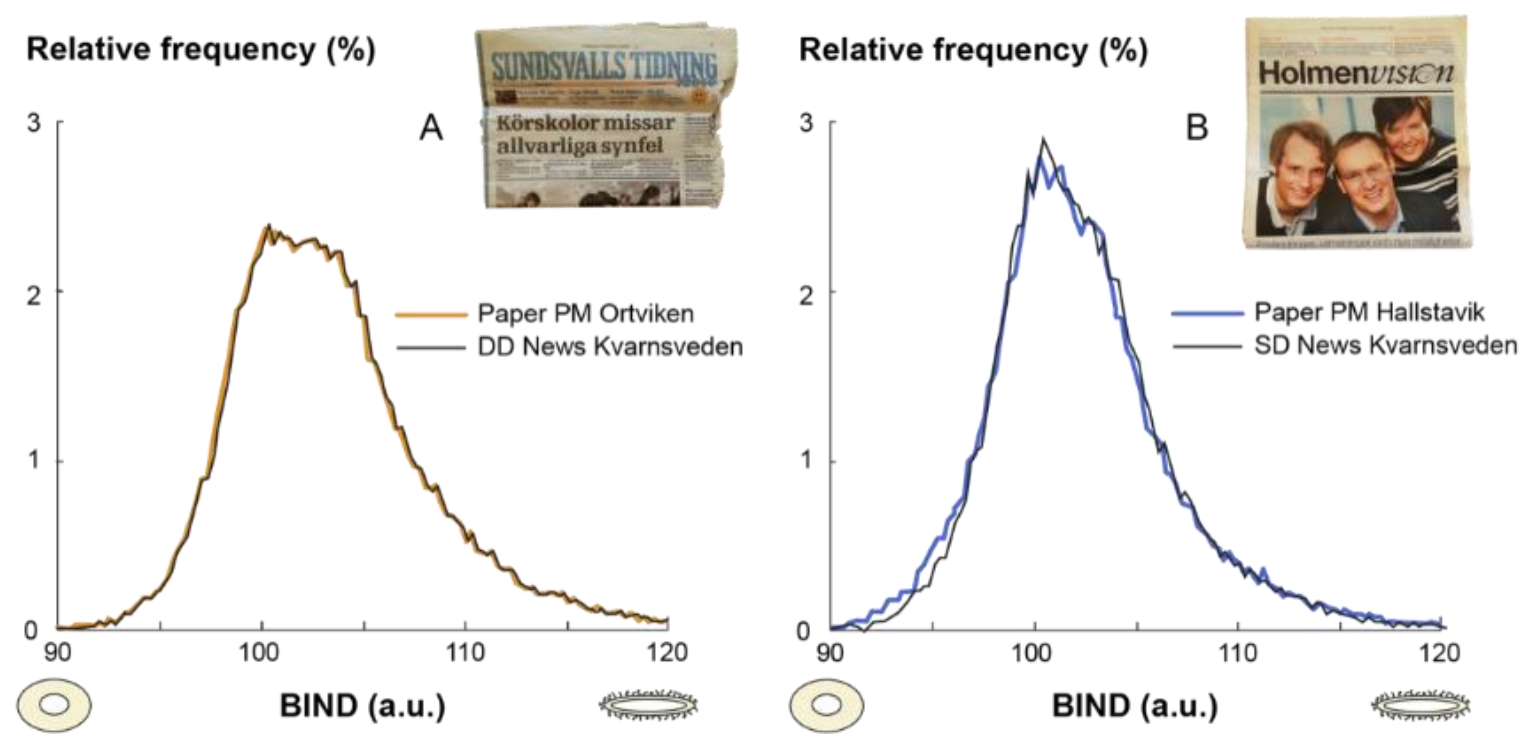

Fig. 10. BIND distribution for paper of news grade and the corresponding furnish 
The authors also analysed disintegrated paper from the magazine produced for internal communication to the personnel at Holmen Paper Hallstavik, Sweden paper mill. This mill only used single-disc refiners in the primary refiner stage, and Norway spruce was the wood raw material. The BIND distribution exhibited a similar "fingerprint" as was shown for the fibres from the single-disc refiners from Kvarnsveden, as shown in Fig. 10B. The authors considered these attempts to yield promising results, the "fingerprint" set early in the first refining stage seemed to still be recognisable in the final paper product, even printed, despite the many process stages involved.

The authors realized that averages may hide some information regarding the nature of the highly heterogeneous material, which is what wood, defibrated wood, and their products are. For instance, the tails, containing extreme values, and the shape of the distribution may be hidden in an average value.

\section{DISCUSSION}

Looking in a microscope at a mechanical pulp it is obvious that it consists of a large number of small particles, which vary greatly in several aspects, such as morphology, length, curl, width, wall thickness, and fibrillation. In spite of this, scientists, mill employees, suppliers, researchers, consultants, etc. commonly describe a pulp in terms of collective properties such as averages of fibre dimensions, handsheet properties, dewatering resistance, etc. In other words, it is common to describe mechanical pulp as a continuum. Variation in a property, such as average fibre wall thickness, may depend on different distributions among the individual particles (Pulkkinen et al. 2006; Vehniäinen 2008), while a given level of tensile index may depend, among other things, on how the fibres have been developed (Reyier Österling 2015; Ferritsius et al. 2020), chemical composition on the surfaces (Rundlöf et al. 1995), and the shives content (Gavelin 1966). Almost a century ago, it was realized that two pulps at the same freeness may consist of fibres with different properties (Maartmann-Moe 1924). Maartmann-Moe (1924) suggests a more detailed analysis of the variations among the individual fibres. Fifty years ago, Atack (1971) highlighted the need for "profound knowledge of fibre properties, of the manner in which they are affected by processing and of their contribution to the end-use requirements of the product". He mentioned relevant basic pulp parameters, such as fibre dimensions and surface area, adapted for the prediction of product quality and continuous monitoring for control.

Although it is common practice (there are some exceptions) to describe mechanical pulps in terms of averages of fibre properties or handsheet properties, such data rarely help to answer the question, "Why did x/y/z happen?" It should also be kept in mind that the particles are never in the "state of handsheets" on their way through the mill. It has been fascinating to see how much may be hidden behind averages of distributions, $c . f$. Rosling et al. (2018), who warn against comparing averages for a more profound understanding of a subject.

Papermakers are still to a great extent specifying their demands on the pulp in terms of dewatering and average length-weighted fibre length, although the correlation to product quality is vague and varies over time. For process control, the operators have had readings of long fibre content and dewatering capability of a pad consisting of billions of particles expressed as a volume of water; this has been the case since the early days of mechanical pulping processes. The main development of what the operators are supposed to control 
has been, first, to get time trends of these variables on a DCS (distributed control system) screen instead of on a piece of paper in the control room, and second, to obtain the readings more frequently with on-line analysers. Properties such as freeness and average lengthweighted fibre length are far from being independent factors. Variations in any of these two properties may depend on variations in a combination of more underlying independent factors. Therefore, it is difficult to know what actions the operators (or a control system) should take to avoid running off specifications. During this time, there has been an immense development of refiner concepts, process design, modelling, use of raw material, fibre characterization, and new products. It is noteworthy to mention that in early times, pulp quality was defined by chewing and tasting the pulp (Atack 1970).

In this paper, the authors presented an approach that aims to describe the heterogeneous nature of the material that consists of particles exhibiting a broad distribution of many measured properties. This paper focuses on describing the character of the longer fibres. The authors applied factor analysis and found that the variations among particle properties, such as fibre wall thickness index, fibre diameter, and external fibrillation, could be explained to levels of approximately $70 \%$ with a single common factor, which is denoted as the BIND. It should be stressed that there is no need to attempt a $100 \%$ explanation, because there are always testing errors present. Because the BIND is calculated from three properties, the variation in the BIND will be reduced compared to data from measurement of a single property, c.f. data reconciliation according to Strand (1987). Furthermore, the more data the operators have to analyse (e.g., distributions of several fibre dimensions), the more difficult it is to get a clear enough picture to take proper actions. In this work, the authors have found that the distribution in the BIND exhibited a characteristic shape depending on the raw material and the process conditions in the primary refiner stage. One of the characteristics is the wideness of the distribution in the BIND. In the study where different raw materials were processed to CTMP in mill scale, it was obvious that the degree of heterogeneity in the raw material was reflected in the BIND distributions of the corresponding CTMPs. Furthermore, the authors identified examples where the shape of the distributions and the kurtosis differed between refiner types. Such differences are impossible to detect by examining averages of fibre dimensions or collective properties such as those from handsheets. A possible explanation for the different levels of kurtosis could be that when both refiner discs were rotating there was more mixing and hence the particles were more homogenously treated. When one of the discs was on a stator, chances may have been higher that some particles passed the refiner gap more towards the stator side and were treated to a lower extent. A high degree of mixing of fibres increases the overall development of the fibres when they are treated as shown by Goosen et al. (2003). However, more studies are needed for deeper insight into the development of the fibres in the refiner gap under different process conditions.

The purpose of a screen room with a reject refiner stage is to fractionate and then develop particles, which the authors believe should be developed further. However, there is no common definition of the efficiency of a screen room. As shown in Fig. 11, there is a rather wide distribution of the particles in the feed to the reject refiner with respect to the BIND. Based on the distribution in the BIND of the feed to the screen room it may be possible to get a rough estimate of what is theoretically possible to fractionate and send to the reject refiner, as shown in Fig. 11. 


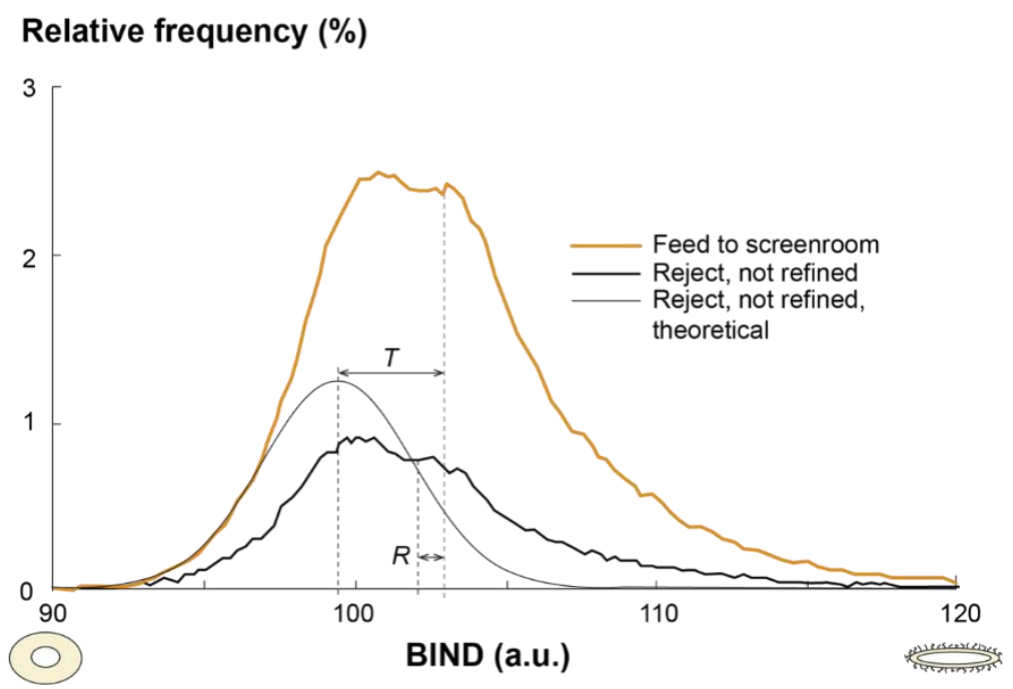

Fig. 11. BIND for primary stage unscreened feed to screen room, feed to reject refiner, and theoretical possible feed to reject refiner in the double-disc line in mill 1 ; dashed line = average

The $R$ parameter shown in the figure corresponds to the difference between the mean BIND of the feed to the screen room and the feed to the reject refiner. The $T$ in the figure corresponds to the difference between the mean BIND of the feed to the screen room and an estimated theoretical minimum mean of a more narrow BIND distribution of the feed to the reject refiner. The efficiency of the screen room may be estimated by dividing $R$ by $T$. In this case, the quotient was $17 \%$. There are of course other values than the mean to define the position of the distributions. The low efficiency means that not only particles of high BIND go to the reject refiner but it also means that particles of relatively low BIND go forward without being developed further. Furthermore, particles in lower levels of BIND require more energy to develop compared to the particles, which exhibit a high level in BIND, c.f. Fig. 7. The amount of well-developed fibres must probably be at a low level in the reject refiner to be able to treat the low-developed fibres in the refiner gap. Studies performed on compressing wood samples in a Split-Hopkins device show that the summerwood fibres begin to be compressed when all spring-wood fibres have been compressed (Moilanen et al. 2016). As long as the fractionation efficiency remains low and the particles with lowest level in BIND are for the most part not developed, the character of the fibres set in the primary refiner stage will largely remain in the final pulp. With low efficiency in both fractionation and treatment of lower bonding fibres, the main focus should be the process conditions in the primary refiner stage and raw material selection. This is supported by Browning and Parker (1970): "Our contention is that good quality groundwood is made on the grinders. No amount of re-screening, refining or any other treatment will affect, to any greater extent, the basic groundwood quality". Hence, the number of process stages may be minimized. Steenberg (1975) argues strongly for stating the wood condition to interpret any description of the influence of the process and its product correctly.

For more than 50 years, the mechanical pulping community has worked on increasing energy efficiency. A lot of progress has been made, but to this day there is no common definition of energy efficiency. There are two "popular" ways to get a value. One is to plot a pulp or handsheet property versus the applied specific energy and compare the slopes and levels to one or more references. However, in this case, there is no attention paid to the feed material. Another way is to take the change in a pulp or handsheet property 
over a process stage and divide it with the applied specific energy. In this case, it is difficult to put a value on the raw material when a primary stage refiner is examined with respect to, e.g., pulp or handsheet properties of wood chips. Furthermore, sometimes it is not possible to make handsheets of the outgoing pulp from a primary stage refiner because it can be too coarse. The distributions in the BIND may provide a possibility to define energy efficiency with respect to the change in the total population or heterogeneity of the particles. As a first attempt the concept may be as follows: The distribution in the BIND for primary stage double-disc TMP and the corresponding TMP of news grade largely overlap, c.f. Fig. 3. The common area of these two distributions was 0.961. If the distributions were identical, the common area would have been 1. Energy efficiency may be defined according to Eq. 3:

$$
\text { Energy efficiency }=(1 \text { - common area }) / \text { specific energy input }
$$

The energy input in the reject stage to develop the primary pulp to news grade was approximately $300 \mathrm{kWh} / \mathrm{bdmt}$. Hence, the energy efficiency for the stage would be 130 $\mathrm{kg} / \mathrm{Wh}$. A similar calculation was done for the refining stage to develop news grade TMP to SC grade TMP, as shown in Fig. 6. The common area of the corresponding distributions was lower, 0.935 . The energy input was $1,100 \mathrm{kWh} / \mathrm{bdmt}$, which gave a lower energy efficiency, $59 \mathrm{~kg} / \mathrm{Wh}$. However, this way of defining the energy efficiency is somewhat challenging when the process stage is a primary stage refiner where the feed material is chips. To overcome this obstacle, the authors examined the BIND distributions of digested CTMP and digested chips in the mill producing CTMP. In other words, the authors took samples before and after a primary stage refiner, digested both samples to the same yield, and analysed them in the same way. The authors did this for the three mixtures of raw materials. The level of energy efficiency ranged from $360 \mathrm{~kg} / \mathrm{Wh}$ to $500 \mathrm{~kg} / \mathrm{Wh}$, see Table 2. Data from the two cases of TMP are also shown in Table 2. The levels of the primary refiner stage were considerably higher compared to examples shown for the later refining stages. Using this approach, it is possible to define energy efficiency for a single operating point of the refiner.

Table 2. Energy Efficiency in a Primary Stage CTMP Refiner for Three Grades of Raw Material (Row 2 Through 4) and for Two Process Stages TMP (Row 5 and 6)

\begin{tabular}{|c|c|c|c|}
\hline Material Feed & Material Out & Common Area & Energy Efficiency (kg/Wh) \\
\hline Saw mill chips & Prim stage CTMP & 0.69 & 500 \\
\hline Mix 50/50 round wood/saw mill & Prim stage CTMP & 0.76 & 400 \\
\hline Round wood chips & Prim stage CTMP & 0.78 & 360 \\
\hline Unscreened TMP & News grade TMP & 0.96 & 130 \\
\hline News grade TMP & SC grade TMP & 0.93 & 59 \\
\hline
\end{tabular}

In this study, the authors propose that the distribution in the BIND of the particles in a pulp may be a way to expand the work to achieve a uniform product quality at minimum cost into areas beyond averages. One such area is the "tails", the extremes at the edges of distributions, where comparatively few particles deserve attention because they may have a strong influence on the properties of products made of a pulp, e.g., missing dots and lint candidates. Another area is the different characteristic shapes of the distributions from single- and double-disc refiners. Furthermore, to obtain relevant values 
of the independent factors it is important that they are based on relevant information about the individual particles, preferably measured on-line. It may be of value to have measures of the structure of the fibre wall (Vehniäinen 2008; Fernando et al. 2011; Lehto 2011). A challenge for the implementation of the BIND approach presented in this paper is that it is rare in the mechanical pulping community to work with distributions among particles as well as independent common factors. A complement to the approach presented may be to examine distributions of conventionally examined fibre properties such as diameter, wall thickness, fibrillation, etc. However, this leads to more data to examine.

Characterizing particles developed in a mechanical pulping process with respect to BIND distributions may yield a more profound understanding of how to control the process, especially how the fingerprint with respect to fibre "bonding" on the particle level is set in the primary stage refiner and altered along the process. The BIND distributions make it possible to evaluate process stages like refining and fractionation in a common way and could open up for simulations of how the wood material is developed along the process with respect to the level of heterogeneity. Another area where distributions of fibre characteristics may be valuable is to understand how the functional properties of the products are influenced. It may be possible to discuss what the properties of different fibres should be instead of what the "average fibre", which does not exist, should be like.

The "bonding" fingerprint may be a valuable complement to the fingerprints with respect to length distribution, fines content, shives content, and preferably information regarding the chemical composition of the surface of the particles. Furthermore, it remains to find key figures based on the distributions, to be a part of a description of the character of the heterogeneous material, which mechanical pulps truly are.

\section{CONCLUSIONS}

1. Wood, pulp, and paper are heterogeneous materials. The authors conclude that using distributions of a common bonding factor, BIND, for each particle is one way to characterize the heterogeneity of mechanical pulp fibres.

2. The authors have found that averages and collective properties may hide valuable information about the character of the fibre population.

3. A characteristic BIND-distribution is set in the primary refiner stage, depending on both wood and process conditions, and remains qualitatively intact along the process.

4. Spruce fibres were developed in refining in such a way that the differences between fibres with low and high BIND increased with energy input, thus resulting in a more heterogenous population.

5. The BIND-distributions may be used to assess the tails of the distributions (extreme values), energy efficiency, and fractionation efficiency. Together with a proper fibre analyser the distributions are well suited for on-line use.

\section{ACKNOWLEDGMENTS}

The authors gratefully appreciate the Swedish Energy Agency, the Knowledge Foundation, and Stora Enso for financial support; partners in the e2mp-program for 
valuable discussions; employees at Stora Enso Skoghall mill and Stora Enso Kvarnsveden mill for stimulating trials and discussions; and Maria Vornanen and Alf Gustafsson at Stora Enso for skillful experimental work.

\section{REFERENCES CITED}

Atack, D. (1970). "Introductory remarks of panel discussion on process control in production of mechanical pulp," in: Proceedings of the Symposium on Mechanical Pulp, Oslo, Norway, pp. 195-197.

Atack, D. (1971). "Characterization of pressurized refined pulp," in: Proceedings of the International Symposium on Paper Pulp Characterization, Ronneby, Sweden.

Browning, B. H., and Parker, J. R. (1970). "The characterization of offset lint and the testing of offset papers," in: Proceedings of the Symposium on Mechanical Pulp, Oslo, Norway, pp. 67-81.

Clark, J. d'A. (1958). "Fundamentals of groundwood evaluation - A new approach," Pulp and Paper Magazine of Canada 59(10), 134-137.

Clark, J. d'A. (1978). Pulp Technology and Treatment for Paper, Miller Freeman Publications, San Francisco, CA, USA.

Fernando, D., Muhic, D., Engstrand, P., and Daniel, G. (2011). "Fundamental understanding of pulp property development under different thermomechanical pulp refining conditions as observed by a new Simons' staining method and SEM observation of the ultrastructure of fibre surfaces," Holzforschung 65(6), 777-786. DOI: 10.1515/HF.2011.076

Ferritsius, O. (1996). "Control of fundamental properties in TMP and SGW production be the use of factor analysis," in: Proceedings of the SPCI 1996 Conference, Stockholm, Sweden, pp. 245-255.

Ferritsius, O., and Ferritsius, R. (1997). "Improved quality control and process design in production of mechanical pulp by the use of factor analysis," in: Proceedings of the International Mechanical Pulping Conference, Stockholm, Sweden, pp. 111-125.

Ferritsius, O., and Ferritsius, R. (2001). "Experiences from Stora Enso mills of using factor analysis for control of pulp and paper quality," in: Proceedings of the International Mechanical Pulping Conference, Helsinki, Finland, pp. 495-503.

Ferritsius, R., and Rautio, M. (2007). "Differences in fibre properties between GW and TMP for magazine grades," in: Proceedings of the International Mechanical Pulping Conference, Minneapolis, MN, USA.

Ferritsius, O., Ferritsius, R., and Reyier, S. (2009). "The influence of process design on the distribution of fundamental fibre parameters," in: Proceedings of the International Mechanical Pulping Conference, Sundsvall, Sweden, pp. 160-168.

Ferritsius, O., Mörseburg, K., and Ferritsius, R. (2014). "BAT of TMP and CTMP plants with respect to quality development and energy efficiency," in: Proceedings of the International Mechanical Pulping Conference, Helsinki, Finland.

Ferritsius, O., Ferritsius, R., and Rundlöf, M. (2018). "Average fibre length as a measure of the amount of long fibres in mechanical pulps-Ranking of pulps may shift," Nordic Pulp \& Paper Research Journal 33(3), 468-481. DOI: 10.1515/npprj-20183058

Ferritsius, R., Sandberg, C., Ferritsius, O., Rundlöf, M., Daniel, G., Mörseburg, K., and Fernando, D. (2020). "Development of fibre properties in mill scale high- and low 
consistency refining of thermomechanical pulp (Part 1)," Nordic Pulp \& Paper Research Journal 35(4), 589-599. DOI: 10.1515/npprj-2020-0027

Forgacs, O. L. (1963). "The characterization of mechanical pulps," Pulp \& Paper Magazine of Canada 64, T89-T116.

Forgacs, O. L., Robertson, A. A., and Mason, S. G. (1957). "The hydrodynamic behaviour of papermaking fibres," in: Transactions of the symposium held at Cambridge, Fundamentals of Papermaking Fibres, Cambridge, UK, pp. 447-473.

Gavelin, N. G. (1966). Science and Technology of Mechanical Pulp Manufacture, Lockwood Publishing Company, Inc., Nottingham, UK.

Goosen, D. R., Olson, J. A., and Kerekes, R. J. (2003). "The role of heterogeneity in compression refining," Journal of Paper Science 33(2), 110-114.

Heikkurinen, A., Levlin, J., and Paulapuro, H. (1991). "Principles and methods in pulp characterization-Basic fiber properties," Paperi ja Puи 73(5), 411-417.

Hill, J., Johansson, L., and Mörseburg, K. (2017). "ATMP pulping of Norway spruce Pulp property development and energy efficiency," Nordic Pulp \& Paper Research Journal 32(1), 70-86. DOI: 10.3183/NPPRJ-2017-32-01-p070-086

Höglund, H., and Wilhelmsson, K. (1993). "The product must determine the choice of wood type in mechanical pulping," in: Proceedings of the International Mechanical Pulping Conference, Oslo, Norway, pp. 1-22.

Høydahl, H., and Dahlqvist, G. (1997). "The dual demand on fibres in SC-paper," in: Proceedings of the International Mechanical Pulping Conference, Stockholm, Sweden, pp. 337-344.

Kure, K. (1999). On the Relationship Between Process Input Variables and Characteristics in Thermomechanical Pulping, Doctoral Thesis, Norwegian University of Science and Technology, Trondheim, Norway.

Lehto, J. (2011). Reinforcement Ability of Mechanical Pulp Fibres, Doctoral Thesis, Aalto University, Helsinki, Finland.

Maartmann-Moe, K. (1924). "Sliperidrift och moderna sliperimaskiner [Grinding operation and modern grinding machines]," Svensk Papperstidning 27(4), 55-59. (In Swedish)

Martorana, E., Ziegler, H., Campo, F. W. A., and Jühe, H. (2006). "Causes of missing dots in rotogravure printing," Wochenblatt für Papierfabrikation 62(12), 722-728.

Mohlin, U. (1989). "Fibre bonding ability - A key pulp parameter for mechanical pulps to be used in printing papers," in: Proceedings of the International Mechanical Pulping Conference, Helsinki, Finland, pp. 49-57.

Moilanen, C., Björkqvist, T., Engberg, B. A., Salminen, L. I., and Saarenrinne, P. (2016). "High strain rate radial compression of Norway spruce earlywood and latewood," Cellulose 23(1), 873-889. DOI: 10.1007/s10570-015-0826-5

Provotas, N., and Uesaka, T. (2003). "Modelling paper structure and paper-press interactions," Journal of Pulp and Paper Science 29(10), 332-340.

Pulkkinen, I., Ala-Kaila, K., and Aittamaa, J. (2006). "Characterization of wood fibers using fiber property distributions," Chemical Engineering and Processing 45(7), 546554.

Reyier, S. (2008). Bonding Ability Distribution of Fibers in Mechanical Pulp Furnishes, Licentiate Thesis, Mid Sweden University, Sundsvall, Sweden.

Reyier, S., Ferritsius, O., and Shagaev, O. (2008). "Measuring the bonding ability distribution of fibers in mechanical pulps," TAPPI Journal 7(12), 26-32. 
Reyier, S., Ferritsius, O., and Ferritsius, R. (2012). "The influence of fiber dimensions on mechanical pulp long fiber tensile index and density," Nordic Pulp \& Paper Research Journal 27(5), 844-859. DOI: 10.3183/NPPRJ-2012-27-05-p844-859

Reyier Österling, S. (2015). Distributions of Fiber Characteristics as a Tool to Evaluate Mechanical Pulps, Doctoral Thesis, Mid Sweden University, Sundsvall, Sweden.

Reme, P. A. (2000). Some Effects of Wood Characteristics and the Pulping Process on Mechanical Pulp Fibres, Doctoral Thesis, Norwegian University of Science and Technology, Trondheim, Norway.

Rosling, H., Rosling Rönnlund A., and Rosling O. (2018). Factfulness, Flatiron Books, New York, NY, USA.

Rundlöf, M., Höglund, M., Htun, M., and Wågberg, L. (1995). "Effect of fines quality on paper properties - New aspects," in: Proceedings of the International Mechanical Pulping Conference, Ottawa, Canada, pp. 109-118.

Steenberg, B. (1975). “A neglected gold mine," in: Proceedings of the International Mechanical Pulping Conference, San Francisco, CA, USA, pp. 125-128.

Steenberg, B. (1957). "Beating and the mechanical properties of paper," in: Transactions of the Symposium Held at Cambridge, Fundamentals of Papermaking Fibres, pp. 229-240.

Strand, B. C. (1987). "Factor analysis as applied to the characterization of high yield pulps," in: Proceedings of the 1987 TAPPI Pulping Conference, pp. 61-66.

Syverud, K., Chinga, G., Johnssen, P.O., Leirset, I., and Wiik, K. (2007). "Analysis of lint particles from full-scale printing trials," Appita Journal 60(4), 286-290.

Vehniäinen, A. (2008). Single Fiber Properties - A Key to the Characteristic Defibration Patterns from Wood to Paper Fibers, Doctoral Thesis, Helsinki University of Technology, Helsinki, Finland.

Westfall, P. H. (2014). "Kurtosis as peakedness, 1905-2014. R.I.P.," The American Statistician 68(3), pp. 191-195.

Wood, J. R., and Karnis, A. (1979). "Distribution of fibre specific surface of papermaking pulps," Pulp and Paper Canada 80(4), 116-122.

Article submitted: February 17, 2021; Peer review completed: May 28, 2021; Revised version received and accepted: November 17, 2021; Published: December 8, 2021. DOI: 10.15376/biores.17.1.763-784 